\title{
Error handling in the classroom: an experimental study of teachers' strategies to foster positive error climate
}

\author{
Annalisa Soncini ${ }^{1}$ (D) Maria Cristina Matteucci ${ }^{1}$ (D) $\cdot$ Fabrizio Butera $^{2}$ (D) \\ Received: 10 January 2020 / Revised: 22 July 2020 / Accepted: 23 July 2020 \\ Published online: 06 August 2020 \\ (C) Instituto Universitário de Ciências Psicológicas, Sociais e da Vida 2020
}

\begin{abstract}
The present research investigated the possibility to foster positive classroom climate, achievement emotions, and adaptive beliefs about errors by manipulating teachers' error handling strategies. Through a pre-post experimental design, teachers' error handling strategies were manipulated during a fictitious lesson in the primary school context. The experimenter, who was presented as an external teacher, carried out the lesson using positive and supportive error handling strategies (experimental condition) or neutral error handling strategies (control condition). The aim was to test differences in pupils' perceived error climate, achievement-related emotions, and error beliefs comparing the two conditions. A total of 108 fifth-grade primary school pupils took part in the research. The main results revealed that dealing with pupils' errors using a constructive and encouraging strategy that supports them in learning from their errors (positive error handling) increased, compared with a neutral error handling, their perception of being in a trustful and supportive learning climate. This study represents the first experimental attempt in which error-related teaching strategies have been directly manipulated to identify their causal impact on primary school pupils' perceived error climate.
\end{abstract}

Keywords Error handling $\cdot$ Error climate $\cdot$ Teachers $\cdot$ Primary school $\cdot$ Emotions

"Your best teacher is your last mistake" is a figure of speech used in different cultures. The idea that learners can learn from their mistakes carries the positive connotation that errors are viewed as an unavoidable part of human life and can be used to improve skills and knowledge. Errors, however, have been defined as "an individual's behaviour or decision that differs unintentionally from a certain norm, prevents the attainment of a specific goal, and it is judged to be incorrect"

Annalisa Soncini

annalisa.soncini2@unibo.it

1 Department of Psychology, University of Bologna, via Filippo Re, 10, 40126 Bologna, Italy

2 Institute of Psychology, University of Lausanne, Quartier UNIL-Mouline, Bâtiment Géopolis, CH-1015 Lausanne, Switzerland 
(Grassinger and Dresel 2017, p. 61). If applied to the school context, this definition highlights the detrimental role of errors in the pursuit of set learning goals and the consequent negative evaluation, namely, poor grades, from teachers. Accordingly, it is a common practice for pupils to hide errors during the learning process. Several studies, however, have shown that errors and failures can be considered the starting point of a deeper learning process, both in educational (e.g. Bray 2011; Kapur 2008; Zamora et al. 2018) and in organizational contexts (Keith and Frese 2005; Rausch et al. 2017). Errors have personal and social connotations and how they are perceived and interpreted depends on individual and situational features (Billett 2012). Thus, the probability that learners learn from their mistakes is higher when they hold constructive beliefs regarding making mistakes (Tulis et al. 2018) and when errors are positively framed in the environment. Research showed that how errors are evaluated and used in learning activities is associated with specific "error cultures", either adaptive or maladaptive to learning (e.g. Oser and Spychiger 2005). Furthermore, perceiving a supportive and constructive "error climate" affects individuals' adaptive reactions following errors (Steuer et al. 2013).

As argued by Mercer and Littleton (2007), learning is a social and communicative process and teachers have a central role in fostering communication and the relation with students during the daily learning activities. Teachers can support and help students to actively participate in the lesson and to change and correct their mistakes and misconceptions through dialogue (Alexander 2000). For instance, mathematics teachers can use several strategies to fruitfully discuss students' mistakes during classroom interaction, providing the opportunity to learn instead of evaluating them (Ingram et al. 2015).

In this study, we focused on the role of teachers in providing students with efficient and supportive feedbacks on mistakes that, in turn, affect the students' perception of error climate (Tulis 2013). Therefore, the present study aimed at enriching the research on the relationship between teachers' practices focused on students' mistakes (Santagata 2005; Tulis 2013), as well as on students' perceptions, beliefs, and emotions. More precisely, the main research question addressed how different error-related teaching strategies (namely, supportive/positive and neutral) could lead to a difference in pupils' perceived error climate, achievement emotions, and error beliefs. In order to do that, an experimental manipulation created ad hoc for this research was carried out in primary schools. To the best of our knowledge, this is the first study that experimentally manipulates the teachers' strategies focused on managing the students' errors (error handling strategies). Furthermore, this study tests these effects on primary school pupils, a sample rarely investigated by previous research on error climate.

In the next three sections, we present a concise literature review on error climate, its related personal and contextual features, and the role of the teacher in creating it. Then, we present the rationale, methodology, and results of the present research. In the last section, we discuss the findings together with their theoretical and practical implications.

\section{Errors in learning and error climate}

A mistake occurs when there is a mismatch between the results of a student's action and the student's or teacher's expectations (Grassinger et al. 2015). Such a mismatch has been considered the starting point of a self-regulation process. Indeed, the perception of an error first leads to an affective reaction toward the error necessary to appraise the situation, followed by a regulation process needed to maintain sufficient levels of motivation. Both emotional changes and motivational regulation then trigger cognitive and metacognitive activities that, in 
turn, promote adequate strategies to face and overcome mistakes (Tulis et al. 2015). However, the whole process (in its emotional, motivational, and cognitive aspects) may be affected by contextual features and personal characteristics that could increase or reduce the possibility of learning from mistakes. Errors, indeed, may help students to develop more profound knowledge (see Kapur 2008; Metcalfe 2017), but at the same time, errors may have a demotivating effect on students (Weinert 1999), resulting in less learning gains.

Extant research suggests that contextual features, such as error climate, have an impact on the possibility to learn from errors. Error climate is defined as the way students' errors are used, treated, and evaluated during the learning process (Steuer et al. 2013). During the class activities, errors can be conceptualized as necessary and essential for learning, and they can be used as an instrument to develop knowledge in an emotionally safe and trustful learning environment (Tulis 2013). In this case, a constructive, encouraging, positive classroom error climate is established. On the contrary, an unfavourable or adverse error climate emerges when supportive communication on errors between the teacher and learners is lacking, and students focus on being negatively evaluated for their mistakes (Tulis 2013).

Several studies showed that positive error climate is related to affective reactions in students (increasing enjoyment, satisfaction, and pride; Tulis and Ainley 2011) and their error-related reactions (Steuer et al. 2013). Other studies found a relationship between dealing positively with mistakes in a supportive context and other learning-related outcomes, such as students' self-efficacy and joy (Kreutzmann et al. 2014), students' positive learning orientation and lower fear of making mistakes (Rach et al. 2013; Zander et al. 2014), students' motivation and positive learning outcomes (Käfer et al. 2019). Moreover, better achievement in mathematics was associated with students' perception of positive error climate, and a small but significant correlation between error climate and achievement was found, both at the student and at the classroom levels (Steuer and Dresel 2015).

\section{The role of teachers in fostering a supportive error climate}

Studies on classroom climate (Jennings and Greenberg 2009), classroom emotional climate (e.g. Reyes et al. 2012), and classroom goal structure (e.g. Meece et al. 2006) pointed out the importance of teachers' strategies and practices in promoting (or not) positive, emotionally higher, and mastery-oriented learning environments, which can foster motivation, positive emotions, and achievement in students (e.g. Murayama and Elliot 2009; Stuhlman and Pianta 2009). The literature on feedback and formative assessment (e.g. Black and Wiliam 2009, 2010; Brookhart 2017) highlighted that teachers may improve the learning process through effective feedback aimed at reducing "discrepancies between current understandings and performance and a learning intention or goal" (Hattie 2009, p. 175). Finally, the literature on argumentation pointed out that teachers should support students to understand and change their misconceptions and mistakes, through different practices such as dialogic teaching (Alexander 2000, 2006) and dialogic methods (see Mercer 2009). As expressed by Carugati and Perret-Clermont (2015), argumentation fosters students' cognitive development and knowledge construction, and according to Greco et al. (2017), teachers can actively help students to develop their points of view.

To sum up, the role of the teacher is crucial in creating an efficient learning context. Indeed, teachers' positive error handling strategies are a particular kind of feedback, focused on errors, that provide students with deeper analytic dialogue on misconceptions through supportive and proper reactions. Furthermore, according to Schleppenbach et al. (2007), by dealing 
appropriately with students' errors and telling them not to be afraid of errors, teachers can create an environment in which students are comfortable in making mistakes.

The empirical research about teachers' error management practices is still limited. An important contribution (Tulis 2013) has studied and subdivided teachers' reactions in response to errors into two clusters: (a) maladaptive (or negative) responses to students' errors (such as ignoring mistakes, criticizing students, redirecting the question to another student, humiliating/laughing, and showing disappointment) and (b) adaptive (or positive) responses to students' errors (i.e. discussing errors with the whole class, asking for a correction to the student him/herself, waiting for the correct reply, emphasizing the learning potential of errors, and preventing negative reactions to a student's mistake from classmates). Following these results, this author argued that students show different attitudes toward errors based on how teachers handle the mistakes in their class, and that the teacher's tolerance toward error may also have a long-term effect on student attitudes toward (learning from) errors. More recently, Käfer et al. (2019) found that teachers' attitude toward mistakes, teachers' responses to student mistakes, and students' perception of the usefulness of mistakes for learning are related to students' individual achievement in English as foreign language class. Furthermore, the same authors concluded that the students' perceptions of teacher's error-friendly attitudes and responses promote their motivation and achievement.

\section{Students' beliefs about errors and emotional reactions}

Beyond contextual features (such as the teacher's attitudes toward errors and the error climate addressed in the previous paragraph), other variables can be considered to explain the learningfrom-error process, namely, students' beliefs about errors and emotional reactions. In this vein, Tulis and Ainley (2011) found a significant association between students' orientation to learning from errors and their on-task emotions after success and failure experiences, thus suggesting that perceiving errors as an important part of the learning process can foster positive emotional reactions in students after making mistakes. Previously, believing that errors are essential and beneficial for one's own learning and improvement was found to affect the selfregulatory strategies adopted in the learning process (Keith and Frese 2005). Likewise, adaptive error beliefs have been shown to foster more adaptive reactions following errors in different domains, beyond students' academic self-concept and mastery goal orientation, and to act as a mediator in their relationship (Tulis et al. 2018).

Beyond students' beliefs, emotional reactions to errors and failure have been found to moderate the learning-from-error process (Tulis et al. 2015). According to these authors, emotions lead to complex changes in both the affective and cognitive aspects of the students' reactions and are a necessary condition for persistent task engagement in the face of obstacles and for learning from errors in general (Tulis et al. 2016). This idea is also supported by the control-value theory of achievement emotions, which has shown that students' achievement emotions influence learning and achievement by affecting learning-related self-regulated processes (e.g. Pekrun 2006; Pekrun and Perry 2014).

\section{The present study}

This paper aims at investigating whether teacher's positive error handling strategies (i.e. adaptive, constructive, and supportive) may impact pupils' perceived error climate, error beliefs, and 
achievement emotions. The first contribution of the present study is to provide an experimental test of this relation. Therefore, the teacher's strategies in dealing with students' mistakes were experimentally manipulated during a lesson conducted by an experimenter who was introduced as a teacher during a regular class. To the best of our knowledge, only a few studies used a quasiexperimental design, based on training teachers and then observing them during their lessons, although they did not directly manipulate the teacher's strategies (Heinze and Reiss 2007; Rach et al. 2013). The rest of the existing research is based on correlational or observational methodologies (Käfer et al. 2019; Santagata 2005; Steuer et al. 2013; Tulis 2013; Tulis et al. 2018).

Second, the literature about error climate has mainly focused on secondary school contexts (Käfer et al. 2019; Rach et al. 2013; Spychiger et al. 2006; Steuer et al. 2013; Steuer and Dresel 2015; Tulis et al. 2018), and only a few studies (Kreutzmann et al. 2014; Zander et al. 2014) were conducted in primary schools. Since teachers are believed to foster a positive error climate through their feedback, behaviour, and responses, studying how teachers deal with students' errors could be even more interesting in those grades in which they manage all the classroom aspects (i.e. teaching, administration, relationship), and are more presents with the students in class, i.e. in primary school.

The study was carried out based on an experimental manipulation (detailed in the "Procedure" section) that opposed positive handling (experimental condition) vs. neutral handling (control condition) of primary school pupils' errors during a lesson in class. In a pre/post-test design, we analyzed the impact of these two error management strategies on the pupils' perception of the error climate established in the class, their beliefs about errors, and their achievement emotions.

Based on the literature reviewed above, we formulated three hypotheses:

H1: We expected a more positive pre/post-test difference in perception of error climate in the positive handling condition than in the neutral handling condition.

$\mathrm{H} 2$ : We expected a more positive pre/post-test difference in error beliefs in the positive handling condition than in the neutral handling condition.

H3: We expected higher perceived enjoyment and lower anxiety in the positive handling condition than in a neutral handling condition.

\section{Method}

\section{Participants}

To determine the sample size, we conducted a power analysis using G*Power 3.1 (Erdfelder et al. 1996). First, we considered Tulis's (2013) findings since this paper investigated perceived error tolerance by the teachers, students' attitude toward errors, and covering up errors. Although this study is correlational, whereas ours is experimental, it is acceptable to use the effect size based on correlations for estimations related to experimental design (Perugini et al. 2018). Thus, we considered the three effect sizes that could be found in this study. The range of the effect sizes was $d=0.54-1.12$ (median $d=0.58$, medium effect, Cohen 1988). The power analysis computed with the smallest effect size $(0.54)$ we found, to be on the safe side, indicated that a total sample of 48 participants was needed to detect a similar effect size, using a repeated measures ANOVA with two measurements $(r=.50)$, with $95 \%$ of power and alpha error probability set to .05 . Second, we collected the effect sizes of studies with quasi- 
experimental design, similar to ours, in which teachers' error-related strategies were manipulated through teachers' training instead of direct manipulation. Rach et al. (2013) found significant results on affective teacher support and students' fear of making mistakes, while Heinze and Reiss (2007), using the same questionnaire as Rach and colleagues, found an impact also on cognitive aspects of teacher behaviour in mistake situations. The range of the five effect sizes found in these studies was $d=0.23-0.67$ (median $d=0.36$, small effect). The power analysis computed with the median effect size we found indicated that a total sample of 104 participants would be needed to find a similar effect size with $95 \%$ power using a repeated measures ANOVA with two measurements $(r=.50)$, with alpha at .05 . Based on these results, we decided to recruit about 50 pupils for each condition, enough to detect a small-medium effect size, and to oversample to allow for drop-out, missing data, and invalid questionnaires.

One hundred and sixty-one pupils from five public Italian primary schools, in the same Northern region in Italy (Emilia-Romagna), were enrolled in the study. Participation was voluntary, and a written consent form was required from the participants' parents. Twenty pupils did not have the consent form for taking part in the research, and, due to the pre-post-test design, we lost 33 participants because pupils missed one of the two parts of the experiment. Therefore, one hundred and eight $(N=108)$ fifth-grade pupils were considered for the analyses, belonging to seven classrooms $\left(M_{\text {pupils per class }}=15.42, S D=6.29\right.$, range $\left.=5-22\right)$. The mean age was 10.38 years, $S D=0.54$, and $53 \%$ were male. In order to divide the sample in the two conditions, each classroom was randomly assigned to one of the two experimental conditions before the data collection started: three classrooms in the neutral handling condition (composed of 22, 19, 22 pupils respectively) and four classrooms in the positive handling condition (composed of 15, 15, 10 , and 5 pupils respectively). Classroom composition was not altered, and pupils participated in the study in their regular classroom; it should be noted that pupils in a classroom do not change as a function of subject or level as in other countries. The positive handling condition had a smaller number of pupils because of the composition of each classroom and only 45 pupils completed all the pre- and post-test measures. The two groups were comparable, since we did not find any significant difference between their characteristics. Table 1 shows additional information about the two groups' composition and the results of chi-square and $t$ tests.

\section{Procedure}

The Ethical Board of the first author's university approved the study protocol (protocol number 0017377). To manipulate the teacher's error handling, we created a script based on Tulis's (2013) findings of video-recoded lessons in Germany, and on Santagata's (2005) results concerning Italian teachers' error handling strategies. The script, explained in detail below, was carried out by the experimenter during a fictitious lesson. The experimenter was presented by the classroom teacher as an external teacher expert in the lesson subject. The lesson was about the "Constitution of the Italian Republic", a topic not related to either literature or science-related subjects, to avoid a gender stereotype effect (Flore and Wicherts 2015). This subject is part of the school programme, and in this respect, it was relevant and realistic. The lesson consisted of 10 slides (created with PowerPoint) in which the experimenter explained the Italian Constitution history and characteristics. The lesson lasted for $1 \mathrm{~h}$. During the lesson, to allow for pupils to make mistakes, the experimenter asked different questions to the whole class or to a specific student. A maximum of 50 questions was asked during the lesson. The experimenter asked a set of pre-determined questions during the lesson (from one to three for each slide), as well as follow-up questions that came out from the discussion. The experimenter bias was limited through several strategies, namely, the standardization of the whole 
Table 1 Composition and characteristic of the experimental (positive handling condition) and control (neutral handling condition) group, results of chi-square test and $t$ test for the difference between the groups

\begin{tabular}{lllll}
\hline & $\begin{array}{l}\text { Experimental group } \\
\text { Positive handling condition }\end{array}$ & $\begin{array}{l}\text { Control group } \\
\text { Neutral handling condition }\end{array}$ & $\chi^{2}(p)$ & $t(p)$ \\
\hline Classroom, $N$ & 4 & 3 & $/$ & \\
Age, mean $(S D)$ & $10.32(0.51)$ & $10.43(0.56)$ & $.209(.648)$ & \\
Gender, $N(\%)$ & & & & \\
Male & $23(51.1)$ & $35(55.6)$ & $/$ & $/$ \\
Female & $22(48.9)$ & $28(44.4)$ & $.793(.373)$ & \\
Pupils, $N(\%)$ & $45(41.7)$ & $63(58.3)$ & $.247(.619)$ & \\
SpLD certifications, $N(\%)$ & $2(4.4)$ & $1(1.6)$ & & \\
Pupils born in Italy, $N(\%)$ & $41(91.1)$ & $59(93.7)$ & & \\
Spoken language, $N(\%)$ & & $54(85.7)$ & & \\
Italian-speaking pupils & $40(88.9)$ & $3(4.8)$ & & \\
Foreign language pupils & $3(6.7)$ & $6(9.5)$ & & \\
Bilingual pupils & $2(4.4)$ & &
\end{tabular}

$p<.05$. SpLD certifications, pupils with specific learning disabilities certifications (e.g. dyslexia), issued by the National Health System

manipulation (sentences, slides, and comments were set in advance and learned by heart), the observation of the procedure during the lesson by a research assistant, and the analysis of the audio recordings of the lessons, which confirmed that the planned procedure was followed in each class. The lesson was carried out in two different ways, according to the experimental conditions: a "positive handling" condition and a "neutral handling" condition.

Positive handling condition The script consisted of an introduction, in which the experimenter said: "You can learn from your mistakes, so it is important to try responding even if you are not sure about the right answer" and by five different error handling strategies, namely:

Discussion with the whole class: The experimenter starts a discussion with the whole class, asking the whole class for (different) solutions. For example: "Ok...Let's see if we will find the right answer together."

Correction by the student him/herself: The experimenter repeats/rephrases the question and/or gives a hint to the pupils in order to get the correct answer. For example: "Think hard and try again!"

Proper wait-time: The experimenter waits at least $5 \mathrm{~s}$ without reformulating the question or giving a hint; this wait-time gave pupils a better chance to answer the question as it gave them the possibility to think and formulate their answers.

Emphasizing the learning potential: The experimenter highlights the pupil's active contribution positively and emphasizes the learning potential of the mistake. For example: "It is not exactly right, but, thanks to your answer, I have understood that something is not very clear, so now I will try to clarify this point.".

Impeding negative classmate reactions: The experimenter stops every kind of embarrassing reaction after a pupil's error, such as classmates' jokes and laughers.

These strategies were adapted from Tulis (2013), in which the author observed Germany teachers using these practices, coded them as "adaptive", and found correlation with students' perception of error-friendly environment in classrooms. 
Neutral handling condition The neutral script consisted of the following introduction: "You can answer my questions, but, please, answer only if you are sure that your answer is correct, otherwise you may make many mistakes!", and by three kinds of responses, namely:

Ignoring mistake: The experimenter ignores the mistake, switches to another topic without any comment.

Redirecting the question to another student: The experimenter picks another pupil to correct the mistake made by the first pupil (the so-called "Bermuda triangle of error correction", Oser and Spychiger 2005).

Focus on the wrong answer: The experimenter replies to the pupils saying the answer is not correct. Example: "No. It is incorrect!"

For example: "No, it is wrong!"- and switching to another pupil: "Can you reply to my question?"

The first two responses were adapted from Tulis (2013) and the third was added by the authors. We chose to add this last one based on Santagata's findings (2005) on the most common teachers' mistakes-handling strategies observed in Italian mathematic lessons that the author called "aggravation". This strategy is quite often used in the Italian classrooms; thus, we decided to add "Focus on the wrong answer" to the neutral condition instead of using other maladaptive strategies identified by Tulis (2013) and by other researchers (e.g. Oser and Spychiger 2005), such as "Humiliate", "Expression of disappointment", and "Criticizing students". These last strategies might cause great discomfort and stress in the pupils. Since the manipulation was carried out in Italian context, in which students are used to receiving negative mistakes-responses (Santagata 2005), we believe that the three responses in our neutral condition can be considered less negative than the responses coded by Tulis (2013). Thus, we called the condition "neutral error handling condition".

All the lessons were audio recorded and observed by an external observer who collected information about the pupils' participation to the lesson (counting the number of pupils who raised hands after the questions) and to monitor the error handling strategies used by the experimenter.

One week before the lesson, the pupils filled out a questionnaire (pre-test), and at the end of the lesson, the pupils were asked to fill out a post-manipulation questionnaire (post-test), both administered by a research assistant. To match the pre-post-tests and questionnaires without disclosing the pupils' identity, we used an anonymous coding system. At the end of the data collection, the pupils were fully debriefed.

\section{Pre-test measures}

Demographics Students were asked to provide information about their gender, age, the class attended, nationality, the spoken language, and the one mostly used at home (to ascertain their ability to understand the wording of the items).

Perceived error climate questionnaire-short version-ECQ_pre (16 items) The questionnaire is designed to assess the students' perception of teachers' affective and behavioural responses to students' errors, the use of error in the learning process, and the classmates' behaviour. It includes 16 items with a 4-point Likert agreement response ranging from 1 "strongly disagree" 
to 4 "strongly agree"(e.g. "During the lesson, for our teacher it is not a problem at all if someone makes a mistake"; "During the lesson, we deeply analyse the errors"). The items were preceded by a statement asking pupils to answer the questionnaire by thinking about the climate established by their main teacher. This short version was created specifically for primary school pupils, based on the 31-item scale created by Steuer et al. (2013). In a pilot study, the short version was translated from German to Italian with the forward-backward procedure and was administered on a sample of Italian primary school children $(N=305,10$ years old, 54\% male). The questionnaire (used as a single factor) showed a good reliability $(\alpha=.75)$.

Error beliefs questionnaire-EB_pre (Tulis et al. 2018) This 5-item questionnaire is aimed to assess the students' beliefs about errors on a 4-point Likert scale from 1 "strongly disagree" to 4 "strongly agree" (example items: "Errors are important for my own learning"; "I can learn a lot from my mistakes"). The scale was translated into Italian by the authors.

\section{Post-test measures}

Error climate questionnaire, ECQ_post The same questionnaire as in the pre-test was administered. In this case, items referred to the (fictitious) lesson just completed, instead of referring to the lessons of their teacher.

Error beliefs questionnaire, EB_post The same questionnaire as in the pre-test was administered in the post-test.

Achievement Emotions Questionnaire-AEQ-ES (Lichtenfeld et al. 2012; Italian version: Raccanello et al. 2019) The scale assesses three main emotions: boredom, anxiety, and enjoyment. It comprises three sections: the emotions felt during the lesson, the emotions felt during the homework, and the emotions felt during a test. In the current study, we used only the section about the emotions felt during the lesson, focusing on anxiety and enjoyment (8item scale, four items for each emotion, e.g. "During this class, I worry that everything is too difficult for me" and "I enjoy this class"). For each item, the scale presents schematic drawings of faces corresponding to the level of emotional intensity to be rated on a 5-point Likert scale, ranging from 1 (not at all) to 5 (very much).

Manipulation check To check whether participants correctly perceived the error manipulation condition, positive vs. neutral, they were asked to answer the following question: "During this lesson, the teacher said that errors are important to learn something new" (yes/no).

\section{Results}

The analyses were performed using Mplus version 8 (Muthén and Muthén 2017) and SPSS version 21.0. Descriptive statistics, internal consistency, bivariate correlations, and intraclass correlations (ICCs) for all the variables (pre- and post-test) are presented in Table 2. All the tests were 2-tailed. 


\section{Manipulation check}

A chi-square test was performed to test if the manipulation was perceived as intended. The result showed a significant effect $\left(\chi^{2}(1)=12.67, p<.001\right)$; as expected, in the positive handling condition, 41 out of 45 pupils replied "yes" to the question "During this lesson, the teacher said that errors are important to learn something new", while in the neutral condition, 25 pupils out of 65 replied "no". Thus, this finding suggests that the participants understood the positive condition. However, it is important to note that in the neutral condition, not all the pupils reported the expected response. A plausible explanation may be the social desirability of the question that reflects the commonly purported belief on mistakes, namely, that errors can improve learning, or the acquiescence bias which leads respondents to answer items with affirmative replies, independently of their content.

\section{Descriptive and preliminary analyses}

First of all, as pupils are nested in classes, we calculated the intraclass correlations of all the variables to estimate the degree of non-independence within classes, using Mplus 8 (Muthén and Muthén 2017). ICCs ranged between .009 and .136, all $p s>.05$. However, an ICC higher than .05 could mean that the independency of the observations (pre-post-test) is violated. Thus, we decided to perform a linear mixed model analysis (Field 2013) to avoid the alpha-errorinflation (Stevens 1996). It is important to note that the ICC scores of the main dependent variables decrease from before to after the manipulation. A possible explanation may be that pupils in the same classroom are differently affected by the manipulation and that the classrooms belonging to the same condition were more similar after the manipulation than before because of the manipulation itself.

\section{Perceived error climate (H1)}

In order to control for the effect of the nested data, we ran a linear mixed model analysis in SPSS. This analysis considers the hierarchical structure of the data, controlling for the belonging to a specific class for all our dependent variables. As for error climate, in order to understand if the classrooms significantly affect the fixed effect of repeated measures and

Table 2 Descriptive statistics and bivariate correlations among the dependent variables

\begin{tabular}{|c|c|c|c|c|c|c|c|c|}
\hline Variable & $M$ & $S D$ & 1 & 2 & 3 & 4 & 5 & 6 \\
\hline 1. Error beliefs_pre & 3.22 & 0.39 & - & $.38 * *$ & $.67 * *$ & .13 & $.22 *$ & -.12 \\
\hline 2. Error climate pre & 3.06 & 0.32 & & - & $.34 * *$ & $.48^{* *}$ & .12 & -.13 \\
\hline 3. Error beliefs_post & 3.25 & 0.46 & & & - & .14 & .19 & -.09 \\
\hline 4. Error climate post & 3.21 & 0.37 & & & & - & $.21 *$ & $-.19 *$ \\
\hline 5. Enjoyment & 3.52 & 1.02 & & & & & - & $-.22 *$ \\
\hline 6. Anxiety & 1.26 & 0.49 & & & & & & - \\
\hline Cronbach's alpha & - & - & .58 & .72 & .76 & .75 & .91 & .50 \\
\hline $\mathrm{ICC}$ & - & - & 0.103 & 0.118 & 0.045 & 0.050 & 0.136 & 0.009 \\
\hline
\end{tabular}

$N=108$ students from 7 classrooms. Error beliefs_pre, error beliefs questionnaire administered at the pre-test; error climate_pre, error climate questionnaire administered at the pre-test; error beliefs_post, error beliefs questionnaire administered at the post-test; error climate_post, error climate questionnaire administered at the post-test; ICC, interclass correlation and level of significance of variance between subjects. ${ }^{*} p<.05 ; * * p<.001$ 
conditions on the error climate questionnaire scores, we compared two different models: one in which the random effects are not allowed (like a repeated measures ANOVA, model 1) with one in which we allow the variation of the intercepts between the classrooms (model 2). The analysis showed a significant variance of the intercept across the classrooms $\left(\chi^{2}(1)=7.50\right.$, $p<.01)$. Indeed, the difference of fits between the two models was significant, resulting in better fit indices for the model $2(-2 L L=158.516, d f=6, \mathrm{AIC}=162.516)$ than for the model 1 $(-2 L L=166.021, d f=5, \mathrm{AIC}=162.516)$. Furthermore, we can state that this difference is significant because it is higher than the critical value of the chi-square with $1 \mathrm{df}(3.84, p<.05$; $6.63, p<.01$ ) (Field 2013). Therefore, we included in our analysis the random effect due to the variance of the intercepts between the classrooms. The Wald statistic $(z=1.174, p=.240)$ was not significant, but we did not look at this value since, according to Field (2013), this statistic is not as reliable as the $-2 L L$ statistic.

Controlling for the random effect, the analysis showed a significant main effect of the repeated measure $(F(1,205.82)=14.03, p<.001, d=0.49)^{1}$, resulting in a more positive error climate after the manipulation $(M=3.21, S D=0.37)$ than before the manipulation $(M=3.06$, $S D=0.33)$, as well as a non-significant effect of condition $(F(1,4.51)=0.16, p=.709)$. However, the hypothesized interaction effect between the condition and the repeated measure was significant $\left(F(1,205.82)=6.37, p=.012, d=0.83^{1}\right)$. The Bonferroni post hoc test revealed a significant difference in the positive condition, resulting in a more positive perceived error climate after the manipulation $(M=3.27, S D=0.40)$, compared with before manipulation $(M=2.98, S D=0.36$; cf. Fig. 1).

\section{Error beliefs (H2)}

To test the effect of the manipulation on the pre-post difference in pupils' beliefs about errors, we performed the same linear mixed model analysis. The analysis showed that model 2 significantly improved the fit $(-2 L L=250.537, d f=6, \mathrm{AIC}=254.537)$, compared with model $1(-2 L L=261.010, d f=5$, AIC $=263.010)$. The intercept across the classrooms varied significantly $\left(\chi^{2}(1)=10.47, p<.01\right)$. Considering model 2 , neither the main effect of time (repeated measure) $(F(1,205.89)=.338, p=.562)$ nor the main effect of condition $(F(1$, $4.60)=.826, p=.409)$ was significant. Also, the interaction was not significant $(F(1$, $205.89)=.014, p=.907)$.

\section{Achievement emotions (H3)}

Achievement emotions were only measured at the post-test. The Anxiety scale showed low reliability $(\alpha=.51)$ and a non-normal distribution $(M=1.26, S D=0.49$, skewness $=3.38$, kurtosis $=13.29)$. This is probably due to a floor effect on three items out of four. Thus, we decided to run a non-parametric test for this variable. On the contrary, a linear mixed model was applied to analyze the Enjoyment sub-scale.

As far as Anxiety is concerned, we used the Mann-Whitney non-parametric test to compare the level of the Anxiety score between the two conditions. The analysis showed a significant difference between the two groups $(U=1.127, z=-2.00, p=.045, d=0.39){ }^{2}$ resulting in a

\footnotetext{
${ }^{1}$ For the linear mixed model effect size computation, see Westfall et al. (2014).

${ }^{2}$ For the Mann-Whitney test effect size computation, see Fritz et al. (2012).
} 
Fig. 1 Mean error climate as a function of conditions (positive handling vs. neutral handling) and repeated measure (time: pre-test and post-test). Error bars represent standard errors. Note: $* p<.05$

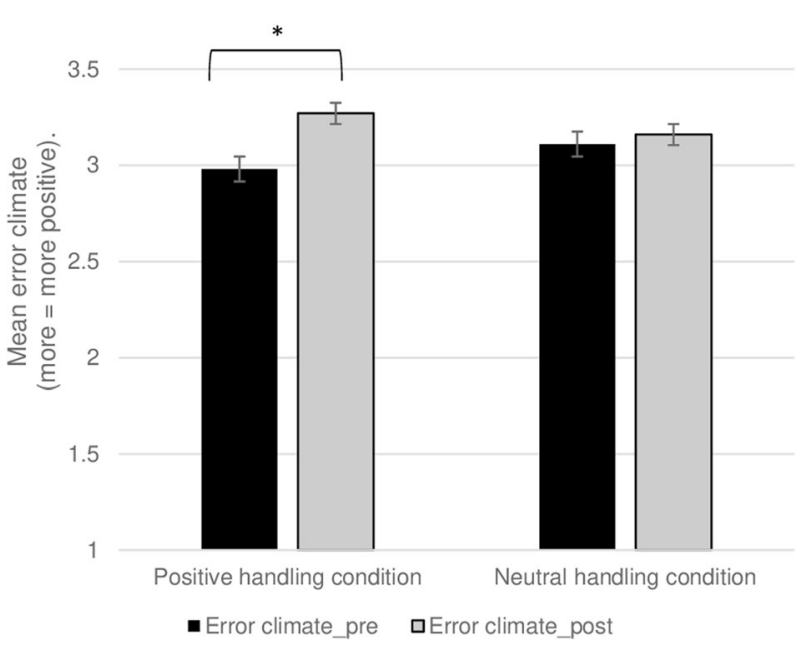

higher level of anxiety in the neutral condition $\left(M d n_{\text {rank }}=59.11\right)$ than in the positive condition $\left(M d n_{\text {rank }}=48.04\right)$. This result has to be prudently interpreted, since the scale had a low reliability.

As for the enjoyment, first of all, we compared a first model without considering the cluster (model 1) with a model in which we allow the variation of the intercept (model 2). The fit of model 2 was better $(-2 L L=302.353, d f=4$, AIC $=306.353)$ than the fit of model $1(-2 L L=$ 307.870, $d f=3, \mathrm{AIC}=309.870)$. The difference between these two models was significant $\left(\chi^{2}(1)=5.52, p<.05\right)$. Considering model 2 , the results showed a non-significant difference on enjoyment $(F(1,4.88)=1.70, p=.251)$ between the two conditions.

\section{Discussion}

In this study, we conducted an experimental test of the hypothesis that different teacher's error handling strategies may affect the pupils' perceived error climate, their personal beliefs about error, and achievement emotions felt during a lesson. We created a pre-post research design, in which we manipulated the teacher's handling of errors and classroom management strategies concerning pupils' errors. Through a fictitious lesson, created ad hoc for the experimental manipulation, pupils' mistakes were managed in either a positive or a neutral way. Thus, during the fictitious lesson, the trained experimenter - in the role of the teacher-aimed to establish either a positive or neutral error climate, by following a script with different responses to pupils' errors. To test our hypotheses, we assessed differences in the perceived classroom error climate before and after the fictitious lesson (H1). Additionally, we also tested the prepost change in pupils' personal error beliefs (H2) and, at the post test, the achievement emotions they felt during the lesson (H3).

\section{Contributions}

The main result of this research is that pupils in the positive handling condition perceived a more positive error climate after the lesson than before, to a greater extent than pupils in the neutral handling condition (H1). The theoretical model elaborated by Tulis et al. (2016) 
describes how individual and contextual features may affect the learning-from-error process. Positive error climate is a central aspect of error-friendly environments, and teachers have a pivotal role in establishing it. Our study, to the best of our knowledge, is the first one that experimentally demonstrated that specific teaching strategies, focused on dealing with errors in a constructive and supportive way, can change the error climate in the classroom. This result is in line with previous studies concerning the link between teachers' error handling strategies, especially their feedback, and the error climate in their classroom (Tulis 2013). However, in previous correlational research on the learning-from-error process (e.g. Tulis et al. 2016), causal claims about how error climate can be established in primary classroom environments were not possible. Indeed, most of the research on teaching and teachers' strategies have used observational methods and videotapes (e.g. Matteucci et al. 2015; Santagata 2005; Tulis 2013) or teachers' training on error handling strategies (e.g. Heinze and Reiss 2007; Rach et al. 2013). Our approach allowed us to directly manipulate the handling of errors using a controlled experimental procedure, and such causal claims are possible in the present study. Therefore, this study contributed to fill the gap in the literature on the role of teachers' strategies in establishing a positive error climate in primary school classrooms.

Another contribution concerns the third hypothesis. We found a significant difference between the two conditions on anxiety, resulting in higher anxiety scale scores in the neutral than in the positive condition. This result could suggest that in the positive handling condition, pupils felt more comfortable during the lesson and they experienced fewer concerns regarding the difficulty of the contents. However, one must interpret this result prudently, since the scale used was not reliable and a floor effect on three items out of four suggested that the instrument was not appropriate for this study. Further research is needed to understand the relation between error handling strategies and achievement emotions.

\section{Limitations}

This study also has some limitations worth noting. Firstly, the second hypothesis was not supported. A possible explanation may be that personal beliefs, derived from experience and years of habituation, can be particularly resistant to change, especially by a time-limited intervention (Murphy and Mason 2006). For example, it has been found that students' personal beliefs (about malleable vs. fixed intelligence) changed over an 8-week workshop (Blackwell et al. 2007), but in a recent 3-day intervention programme, researchers were not able to induce a change in students' general beliefs about intelligence and effort (Lin-Siegler et al. 2016). Thus, it is plausible that, in order to induce a change in beliefs, a longer intervention could be required, thereby allowing a deeper analysis of personal beliefs systems (Grube et al. 1994).

An alternative explanation is that pupils responded to the questionnaire according to a social desirability bias, as in our society, people are supposed to believe that errors are essential for learning. Further research is needed to investigate this issue in order to observe changes more accurately and also distinguish long-term modifications (for example, with a longitudinal study). Moreover, strategies to limit the potential effect of social desirability bias could be implemented.

Secondly, differently from our expectation, we did not find any difference on enjoyment between the two conditions and, due to the low reliability of the anxiety scale (H3), the hypothesis on achievement emotions need to be investigated in a future study, preferably with a different and more appropriate scale. Thirdly, our manipulation was introduced by the experimenter and thus the experimenter expectancy effect could have been at play. Of course, 
as noted above, the implementation of the manipulation was fully controlled through several techniques, such as, for instance, following a pre-determined lesson, using a fixed script for questions and the manipulation, audio-recording and assessing the manipulation with the help of an external observer; however, it was not possible to follow a completely double-blind procedure. This mandatory high standardization of the procedure led to another important limitation of the present study, namely, the limited generalizability of the results. Indeed, the present research is based on a manipulation that simulates a fictitious lesson. We tried to create a context as similar as possible to the real classroom context, but the presence of an external "teacher" and of the data collection procedure made the lesson different from that of a typical day. These two related limitations of our study may be addressed in further research in a different way. For instance, it could be possible to focus on a daily lesson, studying the relationship between students and their regular teacher, combining qualitative and quantitative measures, applying a triangulation of methods. It would be also interesting to train regular teachers in error handling strategies analyzing changes in the pupils during a classical lesson. Fourthly, the number of experimental groups (only seven classrooms) was not enough to run multilevel analyses. Although with linear mixed model analyses we control for the random intercepts due to the hierarchical data, a further study with a higher number of classrooms needs to be conducted.

Finally, we focused only on a small part of the whole Tulis et al.'s (2016) learning-fromerror process. Thus, further research should explore the interconnections between personal features (e.g. errors' beliefs, personal reactions toward errors, ability self-concept) and contextual features (e.g. error climate, classroom achievement goal structure, error handling strategies) that are involved in the learning-from-error process.

\section{Conclusion}

Besides these significant limitations, the present research enriched, we believe, the literature on error climate, with a particular focus on the primary school context, seldom studied so far, and by means of an original experimental design. Overall, our findings have theoretical implications, as they suggest that a supportive and constructive teacher's handling of errors causally affects cognitive aspects involved in the theorized learning-from-error process (Tulis et al. 2016). Considering these results at a more general level, the role of teachers' practices in establishing an effective environment for learning is supported. As argued by Mehan (1979) when the student's reply is not correct, the interaction between the student and the teacher can be extended and teacher's responses support and expand the discussion. Indeed, the positive error handling strategies selected in our manipulation, by providing pupils with prompts on their mistakes, solicited a deeper dialogue and discussion on misconceptions. Dialogue and discussion may, in turn, lead to better learning outcomes, as suggested by literature on argumentation (see Alexander 2006; Greco et al. 2017). Furthermore, the role of teachers in creating a positive and emotionally safe classroom climate has already been supported by a great deal of studies (e.g. Jennings and Greenberg 2009), and we believe that our findings contribute to a better understanding of this process, showing the causal role of error-related strategies.

These considerations lead to some practical implications of this study. As argued by Furtak and Ruiz-Primo (2008) and by Pimentel and McNeill (2013), teachers should become aware of the relevance of promoting dialogue with students and a constructive climate about errors in the classroom in order to ameliorate the learning process. Specifically, better knowledge and 
awareness of the conditions under which using errors may ameliorate the learning process and the (formative) evaluation process (Matteucci et al. 2019), and may contribute to the improvement of the learning/teaching process. With this aim, teachers' professional training programmes may promote teaching practices suitable to allow a safe and supportive environment, where positive and productive effects of error and failure may emerge (Kapur 2008). In this vein, it is important to note that previous research on mathematical education has shown that failure can be a tool for preparing students to benefit from subsequent instruction and that creativity is associated with making errors, which in turn positively influences learning in the longer term (Ziegler and Kapur 2018). It is also worth noting that we found significant and sizeable effects through a short intervention (i.e. a 1-h lesson); we thus consider that if regular class teachers systematically implement supportive and constructive teaching strategies to deal with errors, they may potentially achieve a more fruitful and long-term impact on the establishment of a positive error climate.

In conclusion, future research should investigate further error-related situations in the classroom, for instance, the test situation, in which errors are more salient for the students. Previous research has demonstrated that grades have detrimental effects on students' learning and motivation (e.g. Klapp 2015; Pulfrey et al. 2011, 2013), even on primary school pupils (Hayek et al. 2017); thus, it would be crucial to understand the interplay between error handling strategies and grading in evaluative situations.

Acknowledgements We thank all the school principals, teachers, pupils, and families who accepted to be involved in the research project.

Authors' contributions All authors contributed to the study conception and design. Material preparation and analysis were performed by Annalisa Soncini, Maria Cristina Matteucci, and Fabrizio Butera. Data collection was performed by Annalisa Soncini. The first draft of the manuscript was written by Annalisa Soncini and Maria Cristina Matteucci and revised by Fabrizio Butera. All authors commented on previous versions of the manuscript. All authors read and approved the final manuscript.

Data availability The data that support the findings of this study are available from the corresponding author, Annalisa Soncini, upon reasonable request.

\section{Compliance with ethical standards}

Conflict of interest The authors declare that they have no conflict of interest.

Code availability Not applicable.

\section{References}

Alexander, R. (2000). Culture and pedagogy: international comparisons in primary education. Oxford: Blackwell.

Alexander, R. (2006). Towards dialogic teaching: rethinking classroom talk (Third ed.). Thirsk: Dialogos.

Billett, S. (2012). Errors and learning from errors at work. In J. Bauer \& C. Harteis (Eds.), Human fallibility. Professional and practice-based learning (pp. 17-32). Dordrecht: Springer.

Black, P., \& William, D. (2009). Developing the theory of formative assessment. Educational Assessment, Evaluation and Accountability, 21(1), 5-31. https://doi.org/10.1007/s11092-008-9068-5.

Black, P., \& Wiliam, D. (2010). Inside the Black Box: Raising standards through classroom assessment. Phi Delta Kappan, 92(1), 81-90. https://doi.org/10.1177/003172171009200119 
Blackwell, L. S., Trzesniewski, K. H., \& Dweck, C. S. (2007). Implicit theories of intelligence predict achievement across an adolescent transition: a longitudinal study and an intervention. Child Development, 78(1), 246-263. https://doi.org/10.1111/j.1467-8624.2007.00995.x.

Bray, W. S. (2011). A collective case study of the influence of teachers' beliefs and knowledge on errors handling practices during class discussion of mathematics. Journal of Research in Mathematics Education, 42(1), 2-38. https://doi.org/10.5951/jresematheduc.42.1.0002.

Brookhart, S. M. (2017). How to give effective feedback to your students (2nd ed.). Alexandria: ASCD.

Carugati, F., \& Perret-Clermont, A.-N. (2015). Learning and instruction: social-cognitive perspectives. In D. Wright (Ed.), International encyclopedia of the Social \& behavioral sciences (2nd ed., pp. 670-676). Oxford: Elsevier. https://doi.org/10.1016/B978-0-08-097086-8.92035-X.

Cohen, J. (1988). Statistical power analysis for the behavioral sciences (2nd ed.). Hillsdale: Erlbaum.

Erdfelder, E., Faul, F., \& Buchner, A. (1996). GPOWER: a general power analysis program. Behavior Research Methods, Instruments, \& Computers, 28(1), 1-11. https://doi.org/10.3758/BF03203630.

Field, A. (2013). Discovering statistics using IBM SPSSS statistics (4th ed.). London: Sage Publications Ltd..

Flore, P. C., \& Wicherts, J. M. (2015). Does stereotype threat influence performance of girls in stereotyped domains? A meta-analysis. Journal of School Psychology, 53(1), 25-44. https://doi.org/10.1016/j. jsp.2014.10.002.

Fritz, C. O., Morris, P. E., \& Richler, J. J. (2012). Effect size estimates: current use, calculations, and interpretation. Journal of Experimental Psychology: General, 141(1), 2-18. https://doi.org/10.1037/a0024338.

Furtak, E. M., \& Ruiz-Primo, M. A. (2008). Making students' thinking explicit in writing and discussion: an analysis of formative assessment prompts. Science Education, 92(5), 799-824. https://doi.org/10.1002 /sce. 20270 .

Grassinger, R., \& Dresel, M. (2017). Who learns from errors on a class test? Antecedents and profiles of adaptive reactions to errors in a failure situation. Learning and Individual Differences, 53, 61-68. https://oi. org/10.1016/j.lindif.2016.11.009.

Grassinger, R., Steuer, G., Berner, V. D., Zeinz, H., Scheunpflug, A., \& Dresel, M. (2015). Ausprägung und Entwicklung adaptiver Reaktionen auf Fehler in der Sekundarstuge (Magnitude and changes in adaptive dealing with errors in secondary school). Zeitschrift für Pädagogische Psychologie, 29(3-4), 215-225. https://doi.org/10.1024/1010-0652/a000162.

Greco, S., Mehmet, T., \& Perret-Clermont, A.-N. (2017). Do adult-children dialogical interactions leave space for a full development of argumentation? A case study. Journal of Argumentation in Context, 6(2), 193-219. https://doi.org/10.1075/jaic.6.2.04gre.

Grube, J. W., Mayton, D. M., \& Ball-Rokeach, S. J. (1994). Inducing change in values, attitudes, and behaviors: belief system theory and the method of value self-confrontation. Journal of Social Issues, 50(4), 153-173. https://doi.org/10.1111/j.1540-4560.1994.tb01202.x.

Hattie, J. (2009). Visible learning. A synthesis of over 800 meta-analyses relating to achievement. New York: Routledge.

Hayek, A. S., Toma, C., Guidotti, S., Oberlé, D., \& Butera, F. (2017). Grades degrade group coordination: Deteriorated interactions and performance in a cooperative motor task. European journal of psychology of education, 32(1), 97-112. https://link.springer.com/content/pdf/10.1007/s10212-016-0286-9.pdf.

Heinze, A., \& Reiss, K. (2007). Mistake-handling activities in the mathematics classroom: effects of an in-service teacher training on students' performance in geometry. In J.-H. Woo, H.-C. Lew, K.-S. Park, \& D.-Y. Seo (Eds.), Proceedings of the 31st Conference of the International Group for the Psychology of Mathematics Education (Vol. 3, pp. 9-16). Seoul: PME.

Ingram, J., Pitt, A., \& Baldry, F. (2015). Handling errors as they arise in whole-class interactions. Research in Mathematics Education, 17(3), 183-197. https://doi.org/10.1080/14794802.2015.1098562.

Jennings, P. A., \& Greenberg, M. T. (2009). The prosocial classroom: teacher social and emotional competence in relation to student and classroom outcomes. Journal of Conflict Resolution, 79(6), 925-953. https://doi. org/10.1177/0022002705281667.

Käfer, J., Kuger, S., Klieme, E., \& Kunter, M. (2019). The significance of dealing with mistakes for student achievement and motivation: results of doubly latent multilevel analyses. European Journal of Psychology of Education, 34(4), 731-753. https://doi.org/10.1007/s10212-018-0408-7.

Kapur, M. (2008). Productive failure. Cognition and Instruction, 26(3), 379-424. https://doi.org/10.1080 $/ 07370000802212669$.

Keith, N., \& Frese, M. (2005). Self-regulation in error management training: emotion control and metacognition as mediators of performance effects. Journal of Applied Psychology, 90(4), 677-691. https://doi.org/10.1037 /0021-9010.90.4.677.

Klapp, A. (2015). Does grading affect educational attainment? A longitudinal study. Assessment in Education: Principles, Policy \& Practice, 22(3), 302-323. https://doi.org/10.1080/0969594X.2014.988121. 
Kreutzmann, M., Zander, L., \& Hannover, B. (2014). Versuch macht kluchg? Der umgang mit fehlern auf klassen- und individualebene: Zusammenhänge mit selbstwirksamkeit, anstrengungsbereitschaft und lernfreude von schülerinnen und schülern [Learning by doing? Managing mistakes on the class and individual level: interrelations with students' self-efficacy, effort investment, and joy of learning]. Zeitschrift für Entwicklungspsychologie und Pädagogische Psychologie, 46, 101-113. https://doi. org/10.1026/0049-8637/a000103.

Lichtenfeld, S., Pekrun, R., Stupnisky, R. H., Reiss, K., \& Murayama, K. (2012). Measuring students' emotions in the early years: the achievement emotions questionnaire-elementary school (AEQ-ES). Learning and Individual Differences, 22(2), 190-201. https://doi.org/10.1016/j.lindif.2011.04.009.

Lin-Siegler, X., Ahn, J. N., Chen, J., Fang, F. F. A., \& Luna-Lucero, M. (2016). Even Einstein struggled: effects of learning about great scientists' struggles on high school students' motivation to learn science. Journal of Educational Psychology, 108(3), 314-328. https://doi.org/10.1037/edu0000092.

Matteucci, M. C., Corazza, M., Santagata, R. (2015), Learning from mistakes, or not. An analysis of teachers' error beliefs and mistake-handling strategies through questionnaire and video. In R.V. Nata (Ed.), Progress in Education, Volume 37 (chapter 3) (pp. 33-54), New York, Novascience.

Matteucci, MC., Soncini, A., \& Ciani, A. (2019). From Failure to Success: The Potential Beneficial Role of Error. In A.M. Columbus (Ed.) Advances inPsychology Research. Volume 137 (Chapter 4) (pp. 111-141), New York, Novascience. https://novapublishers.com/shop/advances-in-psychology-researchvolume-137/ ISBN: 978-1-53615-534-1.

Meece, J. L., Anderman, E. M., \& Anderman, L. H. (2006). Classroom goal structure, student motivation, and academic achievement. Annual Review of Psychology, 57(1), 487-503. https://doi.org/10.1146/annurev. psych.56.091103.070258.

Mehan, H. (1979). Learning lessons: social organization in the classroom. Cambridge: MA Harvard University Press.

Mercer, N. (2009). Developing argumentation: lessons learned in the primary school. In N. M. Mirza \& A.-N. Perret-Clermont (Eds.), Argumentation and education: theoretical foundations and practices (pp. 177-194). London: Springer.

Mercer, N., \& Littleton, K. (2007). Dialogue and the development of children's thinking: a sociocultural approach. London: Routledge.

Metcalfe, J. (2017). Learning from errors. Annual Review of Psychology, 68(1), 465-489. https://doi.org/10.1146 /annurev-psych-010416-044022.

Murayama, K., \& Elliot, E. J. (2009). The joint influence of personal achievement goals and classroom goal structures on achievement-relevant outcomes. Journal of Educational Psychology, 101(2), 432-447. https://doi.org/10.1037/a0014221.

Murphy, P. K., \& Mason, L. (2006). Changing knowledge and beliefs. In P. A. Alexander \& P. H. Winne (Eds.), Handbook of educational psychology (pp. 305-324). Mahwah: Lawrence Erlbaum Associates / American Psychological Association.

Muthén, L. K., \& Muthén, B. O. (2017). Mplus user's guide (8th ed.). Los Angeles: Muthén \& Muthén.

Oser, F., \& Spychiger, M. (2005). Lernen ist schmerzhaft [Learning is painful]. Beltz: Weinheim.

Pekrun, R. (2006). The control-value theory of achievement emotions: assumptions, corollaries, and implications for educational research and practice. Educational Psychology Review, 18(4), 315-341. https://doi. org/10.1007/s10648-006-9029-9.

Pekrun, R., \& Perry, R. P. (2014). Control-value theory of achievement emotions. In R. Pekrun \& L. Linnenbrink-Garcia (Eds.), International handbook of emotions in education (pp. 130-151). New York: Routledge.

Perugini, M., Gallucci, M., \& Costantini, G. (2018). A practical primer to power analysis for simple experimental designs. International Review of Social Psychology, 31(1), 1-23. https://doi.org/10.5334/irsp.181.

Pimentel, D. S., \& McNeill, K. (2013). Conducting talk in secondary science classrooms: investigating instructional moves and teachers' beliefs. Science Education, 97(3), 367-394. https://doi.org/10.1002 /sce. 21061

Raccanello, D., Brondino, M., Moè, A., Stupnisky, R., \& Lichtenfeld, S. (2019). Enjoyment, boredom, anxiety in elementary schools in two domains: relations with achievement. The Journal of Experimental Education, 87(3), 449-469. https://doi.org/10.1080/00220973.2018.1448747.

Pulfrey, C., Buchs, C., \& Butera, F. (2011). Why grades engender performance-avoidance goals: The mediating role of autonomous motivation. Journal of Educational Psychology, 103(3), 683-700. https://doi. org/10.1037/a0023911.

Pulfrey, C., Darnon, C., \& Butera, F. (2013). Autonomy and task performance: Explaining the impact of grades on intrinsic motivation. Journal of Educational Psychology, 105(1), 39-57. https://doi.org/10.1037 /a0029376. 
Rach, S., Ufer, S., \& Heinze, A. (2013). Learning from errors: effects of teachers training on students' attitudes towards and their individual use of errors. PNA, 8, 21-30.

Rausch, A., Seifried, J., \& Harteis, C. (2017). Emotions, coping and learning in error situations in the workplace. Journal of Workplace Learning, 29(5), 374-393. https://doi.org/10.1108/JWL-01-2017-0004.

Reyes, M. R., Brackett, M. A., Rivers, S. E., White, M., \& Salovey, P. (2012). Classroom emotional climate, student engagement, and academic achievement. Journal of Educational Psychology, 104(3), 700-712. https://doi.org/10.1037/a0027268.

Santagata, R. (2005). Practices and beliefs in mistake-handling activities: a video study of Italian and US mathematics lessons. Teaching and Teacher Education, 21(5), 491-508. https://doi.org/10.1016/j. tate.2005.03.004.

Schleppenbach, M., Flevares, L. M., Sims, L. M., \& Perry, M. (2007). Teachers' responses to student mistakes in Chinese and U.S. mathematics classrooms. The Elementary School Journal, 108, 131-147 doi: 0013-5984/ 2007/10802-0004\$10.00.

Spychiger, M., Kuster, R., \& Oser, F. (2006). Dimensionen von fehlerkultur in der schule und deren messung [Dimensions of error culture at school and the measuring]. Revue Suisse des Sciences de l'Education, 28, 87-110 Retrieved from: https://www.pedocs.de/frontdoor.php?source opus=4140.

Steuer, G., \& Dresel, M. (2015). A constructive error climate as an element of effective learning environments. Psychological Test and Assessment Modeling, 57, 262-275 Retrieved from: https://www.questia. com/library/journal/1P3-3728625781/a-constructive-error-climate-as-an-element-of-effective.

Steuer, G., Rosentritt-Brunn, G., \& Dresel, M. (2013). Dealing with errors in mathematics classrooms: structure and relevance of perceived error climate. Contemporary Educational Psychology, 38(3), 196-210. https://doi.org/10.1016/j.cedpsych.2013.03.002.

Stevens, J. (1996). Applied multivariate statistics for the social sciences. Mahwah: Lawrence Erlbaum Associates.

Stuhlman, M., \& Pianta, R. (2009). Profiles of educational quality in first grade. The Elementary School Journal, 109(4), 323-342. https://doi.org/10.1086/593936.

Tulis, M. (2013). Error management behavior in classrooms: teachers' responses to student mistakes. Teaching and Teacher Education, 33, 56-68. https://doi.org/10.1016/j.tate.2013.02.003.

Tulis, M., \& Ainley, M. (2011). Interest, enjoyment and pride after failure experiences? Predictors of students' state-emotions after success and failure during learning in mathematics. Educational Psychology, 31(7), 779-807. https://doi.org/10.1080/01443410.2011.608524.

Tulis, M., Steuer, G., \& Dresel, M. (2015). Learning from errors: process and contextual conditions. Towards a model of individual process within contexts. In M. Gartmeir, H. Graber, T. Hascher, \& H. Heid (Eds.), Fehler: Ihre Funktinonen im Kontext Individueller und gesellschaftlicher Entmckliung [Mistakes: their functions in the context of individual and social development] (pp. 53-70). Munster: Waunann.

Tulis, M., Steuer, G., \& Dresel, M. (2016). Learning from errors: a model of individual processes. Frontline Learning Research, 4, 12-26. https://doi.org/10.14786/flr.v4i2.168.

Tulis, M., Steuer, G., \& Dresel, M. (2018). Positive beliefs about errors as an important element of adaptive individual dealing with errors during academic learning. Educational Psychology, 38(2), 139-158. https://doi.org/10.1080/01443410.2017.1384536.

Weinert, B. (1999). Aus Fehlern lernen und Fehler vermeiden lernen [Learning from errors and learning to avoid errors]. In W. Althof (Ed.), Fehlerwelten: Vom fehlermachen und lernen aus fehlern [Error worlds: error making and learning from errors] (pp. 101-109). Opladen: Leske.

Westfall, J., Kenny, D. A., \& Judd, C. M. (2014). Statistical power and optimal design in experiments in which samples of participants respond to samples of stimuli. Journal of Experimental Psychology: General, 143(5), 2020-2045. https://doi.org/10.1037/xge0000014.

Zamora, A., Súarez, J. M., \& Ardura, D. (2018). A model of the role of error detection and self-regulation in academic performance. The Journal of Educational Research, 111(5), 595-602. https://doi.org/10.1080 /00220671.2017.349072.

Zander, L., Kreutzmann, M., \& Wolter, I. (2014). Constructive handling of mistakes in the classroom: the conjoint power of collaborative networks and self-efficacy beliefs. Zeitschrift für Erziehungswissenschaft, 17(S5), 205-223. https://doi.org/10.1007/s11618-014-0558-6.

Ziegler, E., \& Kapur, M. (2018). The interplay of creativity, failure and learning in generating algebra problems. Thinking Skills and Creativity, 30, 64-75. https://doi.org/10.1016/j.tsc.2018.03.009.

Publisher's note Springer Nature remains neutral with regard to jurisdictional claims in published maps and institutional affiliations. 
Annalisa Soncini. Department of Psychology, University of Bologna, via Filippo Re, 10, 40126, Bologna (BO), Italy. Email: annalisa.soncini2@unibo.it.

Current themes of research:

Assessment in education. Errors handling. Error climate.

Most relevant publication in the field of Psychology of Education:

Matteucci, M. C., Soncini, A., \& Ciani, A. (2019). From failure to success: The potential beneficial role of error. In A. M. Columbus (Ed.), Advances in Psychology Research (pp. 112-136). New York: Nova Science Publisher Inc.

Maria Cristina Matteucci. Department of Psychology, University of Bologna, via Filippo Re, 10, 40126, Bologna (BO), Italy. Email: mariacristina.matteucci@unibo.it

Current themes of research:

Teachers' beliefs and attitudes. Students' quality of life and psychological well-being. Casual attribution and responsibility ascription in educational contexts. School psychology.

Most relevant publications in the field of Psychology of Education:

Matteucci, M. C., Scalone, L., Tomasetto, C., Cavrini, G., Selleri, P. (2019). Health-related Quality of life and psychological wellbeing of children with Specific Learning Disorders and their mothers. Research in Developmental Disabilities, 87, 43-53.

Matteucci, M.C \& Farrell, P.T. (2018). School Psychologists in the Italian Education System. A Mixed-Methods Study of a district in Northern Italy. International Journal of School \& Educational Psychology. doi: https://doi.org/10.1080/21683603.2018.1443858

Matteucci, M.C. \& Helker, K. (2018). Who is responsible for educational outcomes? Responsibility ascriptions for educational outcomes in a sample of Italian teachers, parents, and students. Learning and Individual Differences, 61, 239-249. doi: https://doi.org/10.1016/j.lindif.2017.12.009

Matteucci, M.C. (2017). Attributional Retraining and Achievement Goals: An Exploratory Study on Theoretical and Empirical Relationship Reconversion Attributionnelle et Buts D'accomplissement: Une Contribution Exploratoire des Connexions Theoriques et Empiriques. European Review of Applied Psychology / Revue Européenne de Psychologie Appliquée, 67(5), 279-289. doi: https://doi.org/10.1016/j.erap.2017.08.004

Matteucci, M.C, Guglielmi, D., \& Lauermann, F. (2017). Teachers' Sense of Responsibility for Educational Outcomes and Its Associations with Teachers' Instructional Approaches and Professional Wellbeing. Social Psychology of Education, 20(2), 275-298. doi: https://doi.org/10.1007/s11218-017-9369-y

Fabrizio Butera. Institute of Psychology, University of Lausanne, Quartier UNIL-Mouline, Bâtiment Géopolis, CH-1015 Lausanne, Switzerland. Email: fabrizio.butera@unil.ch

Current themes of research:

Group processes. Motivation and goal setting. Socio-cognitive regulation. Assessment in education and school selection. Cooperative learning.

Most relevant publications in the field of Psychology of Education:

Autin, F., Batruch, A., \& Butera, F. (2019). The function of selection of assessment leads evaluators to artificially create the social class achievement gap. Journal of Educational Psychology, 111, 717-735. doi: https://oi. org/10.1037/edu0000307

Pulfrey, C., \& Butera, F. (2018). The good cheat. In-group benevolence and the justification of collective cheating. Journal of Educational Psychology, 110, 764-784. 
Hayek, A.S., Toma, C., Guidotti, S., Oberlé, D., \& Butera, F. (2017). Grades degrade group coordination: deteriorated interactions and performance in a cooperative motor task. European Journal of Psychology of Education, 32, 97-112. doi: https://doi.org/10.1007/s10212-016-0286-9

Sommet, N., Pillaud, V., Meuleman, B., \& Butera, F. (2017). The socialization of performance goals. Contemporary Educational Psychology, 49, 337-354. doi: https://doi.org/10.1016/j.cedpsych.2017.03.008

Sommet, N., Darnon, C., \& Butera, F. (2015). To confirm or to conform? Performance goals as a regulator of conflict with more competent others. Journal of Educational Psychology, 107, 580-598. doi: https://oi. org/10.1037/a0037240 